\title{
The anemia of the old and oldest-old patients hospitalized in Internal Medicine: a very high rate of anemia of chronic disease and multifactorial anemia
}

\author{
Federico Silvestri, ${ }^{1}$ Renzo Pozzo, ${ }^{2}$ Andrea Barbi, ${ }^{1}$ Antonella Labombarda, ${ }^{1}$ Marco Zaramella, ${ }^{1}$ Igor Bramuzzo, ${ }^{1}$ \\ Elisa Mansutti, ${ }^{1}$ Laura Perale, ${ }^{1}$ Adolfo Rogato, ${ }^{1}$ Francesca Zanini ${ }^{1}$ \\ ${ }^{1}$ Internal Medicine Division, Civil Hospital, Latisana (UD); and ${ }^{2}$ Department of Medical and Biological Sciences, University \\ of Udine, Italy
}

\begin{abstract}
Anemia is highly prevalent among the elderly, and few previous studies have focused on hospitalized medical patients aged $\geq 75$ years. During the four months of this single-center prospective cohort study, 508 patients were admitted and studied with a standardized set of blood tests. Anemia, as defined by the World Health Organization, was present in 277 (54.5\%) patients; in the majority of cases it was mild (71.8\%), normocytic $(82.8 \%)$, and hypoproliferative $(90.5 \%)$. The most frequent diagnosis was multifactorial anemia (47.7\%); anemia of chronic disease was the most frequent single cause $(28.5 \%)$ and the most frequent etiologic co-factor among multifactorial anemia. Iron deficiency was found in $22.7 \%$ of cases; vitamin B12 and folate deficiencies were found in $7.5 \%$ and $26.1 \%$, respectively; chronic kidney disease in $16.2 \%$; overt bleeding anemias in $4.8 \%$ and clonal hemopathies in $3.2 \%$. Unexplained anemia was diagnosed only in $5.1 \%$ of cases. The finding of a very high frequency of anemia of chronic disease and multifactorial anemia has implications on both the diagnostic and therapeutic grounds.
\end{abstract}

\section{Introduction}

The definition of elderly (people $\geq 65$ years) has been recently reconsidered since the progressive aging of the population and the increase in the number of

Correspondence: Federico Silvestri, Division of Internal Medicine, Civil Hospital, via Sabbionera 45, 33053 Latisana (UD), Italy.

E-mail address: silvestrifederico@alice.it

Key words: Anemia; internal medicine; elderly.

Contributions: all authors contributed to conception and design of the study, data collection, analysis, and interpretation, and revision of the article; FS drafted the article.

Conflict of interests: the authors declare no potential conflict of interests.

Availability of data and materials: data and materials are available on patients hospital charts.

Ethics approval and consent to participate: ethics approval was not required. Consent was given.

Received for publication: 31 March 2020.

Revision received: 28 April 2020

Accepted for publication: 28 April 2020.

This work is licensed under a Creative Commons Attribution NonCommercial 4.0 License (CC BY-NC 4.0).

${ }^{\circ}$ Copyright: the Author(s), 2020

Licensee PAGEPress, Italy

Italian Journal of Medicine 2020; 14:143-150

doi:10.4081/itjm.2020.1282 healthy people in good shape in their 60 s and early $70 \mathrm{~s}$ has prompted to define the population of elderly as those oldest than 75 . Although there are several ways to classify this population and different definitions are in use, for the purpose of this study, the definitions of old for those 75-84 years and oldest-old for those $\geq 85$ years of age will be used. ${ }^{1,2}$

The increasing number of people in these age groups, the fastest-growing segment of the population in most western countries, ${ }^{2}$ also reflects on the proportion of patients admitted to Internal Medicine wards, i.e., in our area $(250,000$ inhabitants and four County Hospitals), during 2018, on 9119 admissions, the percentage of patients $\geq 75$ years was $68.0 \%$ and that of patients $\geq 85$ years was $34.0 \%$.

Since anemia was found to affect $27 \%$ of the world population ${ }^{3}$ and its prevalence increases with aging (range 3\%-50\% with a mean of $17 \%$ in the cohort of people older than 65 years of age in a systematic review of 34 studies, with peaks of over $50 \%$ in hospitalized patients ${ }^{4}$ ), and few previous studies have focused on old and oldest-old hospitalized medical patients, we have investigated prevalence and etiology of anemia in a population of such patients admitted to a single institution.

\section{Materials and Methods}

We carried out a prospective, observational study on a cohort of consecutive patients aged $\geq 75$ years admitted over four months to the Internal 
Medicine ward of a secondary-care Hospital serving a population of approximately 100,000 inhabitants.

In all patients, after consent was given, a standardized set of blood tests was performed at admission: complete blood count, serum ferritin (SF), serum iron and transferrin (Tf), transferrin saturation (TSat), glomerular filtration rate (GFR) calculated by the Chronic Kidney Disease Epidemiology Collaboration (CKD-EPI) equation, ${ }^{5}$ and C-reactive protein (CRP).

In all anemic patients, further tests were performed: reticulocyte count and index (RI), lactatedehydrogenase (LDH), folate and vitamin B12, thyrotropin stimulating hormone (TSH), free thyroxine (FT4) and serum erythropoietin (EPO). Patients with reticulocyte count $>100 \times 10^{3} / \mu \mathrm{L}$ or $\mathrm{LDH}>450 \mathrm{U} / \mathrm{L}$, underwent haptoglobin and Coombs' direct test (DAT).

All laboratory tests were performed in our central laboratory by standard methods.

Any additional analyses were performed at discretion of the treating physician.

The diagnosis of anemia was based on World Health Organization (WHO) criteria $^{6}$ [hemoglobin $(\mathrm{Hb})<130 \mathrm{~g} / \mathrm{L}$ for males and $<120 \mathrm{~g} / \mathrm{L}$ for females] and the severity level was defined as mild ( $\mathrm{Hb} \geq 100$ $\mathrm{g} / \mathrm{L})$, moderate $(80-99 \mathrm{~g} / \mathrm{L})$ and severe $(<80 \mathrm{~g} / \mathrm{L})$. Only the first $\mathrm{Hb}$ value measured at hospital admission was considered.

To identify types of anemia according to etiology, anemias were classified as follow: i) iron deficiency anemia (IDA) if SF was $<100 \mu \mathrm{g} / \mathrm{dL}$ and TSat was $<20 \%$; ii) anemia of chronic disease (ACD) if SF was $>100 \mu \mathrm{g} / \mathrm{dL}$ and CRP $>10 \mathrm{mg} / \mathrm{L}$ or a clinical diagnosis of acute or chronic infection, malignancy, or inflammatory disease was present; iii) ACD with IDA if SF was $<100 \mu \mathrm{g} / \mathrm{dL}$ and TSat $<20 \%$, with CRP $>10$ $\mathrm{mg} / \mathrm{L}$; iv) vitamin B12 or folate deficiency for serum levels $<200 \mathrm{pg} / \mathrm{mL}$ and $<3 \mathrm{ng} / \mathrm{mL}$ respectively; v) anemia of CKD for GFR $<30 \mathrm{~mL} / \mathrm{min} / 1.73 \mathrm{~m}^{2}$; vi) anemia related to clonal hemopaty and overt bleeding anemias were diagnosed on the basis of anamnesis and laboratory tests; vii) anemia due to hypothyroidism for FT4 $<0.88 \mathrm{ng} / \mathrm{dL}$ with any level of TSH or TSH $>4.0$ $\mathrm{mUI} / \mathrm{L}$ with FT4 in the low-normal range; viii) anemia due to myelodysplastic syndrome (MDS) was suspected on the basis of otherwise unexplained cytopenias \pm monocytosis $>1000 / \mu \mathrm{L}$; ix) anemia was considered multifactorial (MFA) if two or more criteria were present; $x$ ) unexplained anemia (UA) was an exclusion diagnosis, in the presence of normal laboratory parameters.

\section{Statistical analysis}

Data are presented as absolute numbers, mean \pm standard deviation (SD), range, and percentage. Chi-squared and t-Student tests were used to compare study variables. All P-values were two-sided, with the level of significance set at $\leq 0.05$. Pearson's correlation coefficient $r$ was calculated to assess the potential relationship between parameters. All analyses were performed using the Statistica V10 (Stat Soft, Inc.) software.

\section{Results}

During the study-period, 508 individuals aged $\geq 75$ years were admitted, of which 277 (54.5\%, 142 males and 135 females) resulted to be anemic.

Demographic characteristics of the whole population studied are reported in Table 1: compared to females, males were significantly more represented in the anemic group $(\mathrm{P}=0.011)$, but there was no difference in mean age between the two populations. Nevertheless, females were significantly older than males in both groups $(\mathrm{P}<0.01)$.

Among anemics, 15 patients were excluded from further analysis since 2 of them were known as carriers of thalassemia trait, and 13 were admitted for overt bleeding. Causes of bleeding were identified in 11 patients: 3 soft tissue bleedings on warfarin; 3 bleedings from colic diverticula; 2 from ulcer and erosive gastritis; 1 from angiodysplasias; 1 from

Table 1. Demographic characteristics of the population enrolled in the study (No. 508).

\begin{tabular}{lccc}
\hline & Non-anemic (\%) & Anemic (\%) & P-value \\
\hline All patients & $231(45.5)$ & $277(54.5)$ & - \\
\hline Male & $93(39.6)$ & $142(60.4)$ & 0.011 \\
\hline Female & $138(50.5)$ & $135(49.5)$ & \\
\hline Mean age \pm SD & $83.4 \pm 5.7$ & $83.7 \pm 6.2$ & 0.555 \\
\hline Mean age \pm SD male & $81.9 \pm 4.9^{*}$ & $81.8 \pm 5.3^{*}$ & 0.918 \\
\hline Mean age \pm SD female & $84.4 \pm 6.0^{*}$ & $85.8 \pm 6.0^{*}$ & 0.072
\end{tabular}

SD, standard deviation. *In both groups, females were significantly older than males $(\mathrm{P}<0.01)$. 
ulcerative colitis and 1 post hip prosthesis. One patient died before endoscopic tests were performed, 1 patient refused.

The characteristics of the remaining 262 patients are illustrated below.

\section{Hemoglobin}

Mean $\mathrm{Hb}$ concentration was $106 \pm 15 \mathrm{~g} / \mathrm{L}$ (range 44-129), significantly lower in females than in males $(103 \pm 15$ vs $109 \pm 15, \mathrm{P}<0.01)$ with no statistically significant differences among age groups (75-84 vs $\geq 85$ ): $\mathrm{P}=0.799$ among males and $\mathrm{P}=0.270$ among females.

Table 2 shows how 14 patients (5.3\%) had severe anemia, $60(22.9 \%)$ moderate anemia, and the majority (No. 118, 71.8\%) mild anemia. This group of patients was significantly more numerous than the others $(\mathrm{P}=0.001)$, while there were no differences throughout levels of severity among sexes and agegroups. A subgroup of 91 patients (34.7 of the total) had very mild anemia $(\geq 120 \mathrm{~g} / \mathrm{L}$ for males and $\geq 110$ $\mathrm{g} / \mathrm{L}$ for females).

\section{Characteristics of anemia}

In Tables 3 and 4, the main characteristics of anemia are presented. No statistical differences among sexes were found for all values but TSat $>20 \%$, more frequent among males $(\mathrm{P}=0.028)$.

Table 2. Anemia prevalence by severity, sex, and age-group*.

\begin{tabular}{|c|c|c|c|c|c|c|c|c|}
\hline Patient No. & $\begin{array}{c}\text { Very mild } \\
\text { anemia } \\
\mathrm{Hb} \geq 110 \mathrm{~g} / \mathrm{L} \\
\text { female } \\
\mathrm{Hb} \geq 120 \mathrm{~g} / \mathrm{L} \\
\text { male }\end{array}$ & P-value & $\begin{array}{c}\text { Mild } \\
\text { anemia } \\
\mathrm{Hb} \geq 100 \mathrm{~g} / \mathrm{L}\end{array}$ & P-value & $\begin{array}{c}\text { Moderate } \\
\text { anemia } \\
\text { Hb 80-99 g/L }\end{array}$ & P-value & $\begin{array}{c}\text { Severe } \\
\text { anemia } \\
\mathbf{H b}<\mathbf{8 0} \mathrm{g} / \mathrm{L}\end{array}$ & P-value \\
\hline All patients $262^{*}$ & $91(34.7)$ & - & $188(71.8)$ & - & $60(22.9)$ & & $14(5.3)$ & $<0.001$ \\
\hline $\begin{array}{l}\text { Sex } \\
\text { Male } 136 \\
\text { Female } 126\end{array}$ & $\begin{array}{l}42(30.9) \\
49(38.9)\end{array}$ & 0.344 & $\begin{array}{c}105(77.2) \\
83(65.9)\end{array}$ & 0.408 & $\begin{array}{l}24(17.6) \\
36(28.6)\end{array}$ & 0.096 & $\begin{array}{l}7(5.1) \\
7(5.6)\end{array}$ & 0.889 \\
\hline $\begin{array}{l}\text { Age } \\
75-84 \text { y } 151 \\
\geq 85 \text { y } 111\end{array}$ & $\begin{array}{l}54(35.8) \\
37(33.3)\end{array}$ & 0.776 & $\begin{array}{c}107(70.9) \\
81(73.0)\end{array}$ & 0.879 & $\begin{array}{l}38(25.2) \\
22(19.8)\end{array}$ & 0.418 & $\begin{array}{l}6(4.0) \\
8(7.2)\end{array}$ & 0.276 \\
\hline
\end{tabular}

$\mathrm{Hb}$, hemoglobin. *No. 262, after exclusion of overt bleeding anemias and thalassemia trait.

Table 3. Characteristics of anemia (No. 262, after exclusion of overt bleeding anemias and thalassemia trait).

\begin{tabular}{llc}
\hline Parameters & & No. $(\%)$ \\
\hline MCV (fL) & $>100$ & $30(11.5)$ \\
& $80-100$ & $217(82.8)$ \\
\hline Iron & $<80$ & $15(5.7)$ \\
\hline Tf & $<60 \mu \mathrm{g} / \mathrm{dL}$ & $210(80.2)$ \\
\hline TSat $(\%)$ & $<212 \mathrm{mg} / \mathrm{dL}$ & $200(76.3)$ \\
\hline Ferritin $(\mathrm{ng} / \mathrm{mL})$ & $\leq 20$ & $188(71.8)$ \\
\hline Reticulocytes & $>20$ & $74(28.2)$ \\
\hline CRP & $\leq 100$ & $77(29.4)$ \\
\hline Vitamin B12* & $>100$ & $185(70.6)$ \\
\hline Folic acid* & $<100 \times 10^{3} / \mu \mathrm{L}$ & $237(90.5)$ \\
\hline GFR (mL/min/1.73 $\left.\mathrm{m}^{2}\right)$ & $>10 \mathrm{mg} / \mathrm{L}$ & $185(70.6)$ \\
& $<200 \mathrm{ng} / \mathrm{mL}$ & $19(7.5)$ \\
\hline
\end{tabular}

*On 253 cases (130 males and 123 females), after exclusion of 9 cases on therapy with vit B12 and folates; ${ }^{\circ}$ stages of chronic kidney disease. MCV, mean corpuscular volume; Tf, transferrin; TSat, transferrin saturation; CRP, C-reactive protein; GFR, glomerular filtration rate. 


\section{Mean corpuscular volume}

Mean \pm SD mean corpuscular volume (MCV) was 91.6 \pm 8.6 (range 64-135); there were only $15(5.7 \%)$ microcytic anemias $(\mathrm{MCV}<80 \mathrm{fL})$, and $30(11.5 \%)$ macrocytic (MCV $>100 \mathrm{fL})$, with the majority of patients (No. 217, 82.8\%) affected by normocytic anemia.

In Table 4, the distribution of anemia types according to MCV is shown.

Among the 15 patients with microcytic anemia, 9 had IDA, only 3 of which isolated. Among the 30 patients with macrocytic anemia, 9 had isolated ACD, only 1 had vitamin B12 deficiency, 2 isolated CKD, and 1 had MDS. Among 217 normocytic anemias, 16 were affected by isolated IDA, 68 by isolated ACD, 1 by folate deficiency, 5 by CKD only, and 7 by clonal hemopathy. All other cases were included among MFA.

\section{Iron status}

The majority of patients (80.2\%) had hypoferremia, and $76.3 \%$ had low serum Tf; TSat was $\leq 20 \%$ in $71.8 \%$ of cases while SF was $>100 \mathrm{ng} / \mathrm{mL}$ in $70.6 \%$ of patients.

\section{Reticulocytes}

Two hundred and thirty-seven patients $(90.5 \%)$ had a reticulocyte count $<100 \times 10^{3} / \mu \mathrm{L}$ corresponding to $236(90.1 \%)$ with a $\mathrm{RI}<2$.
The majority of cases with a RI $\geq 2$ were on therapy with vitamins or iron, and 2 cases had autoimmune hemolytic anemia (AIHA).

\section{Inflammation}

One hundred and eighty-five patients $(70.6 \%)$ had a CRP $>10 \mathrm{mg} / \mathrm{L}$.

\section{Vitamins deficiency}

After exclusion of patients on therapy with vitamins, of the $19 / 253$ patients $(7.5 \%)$ with vitamin B12 deficiency, only 6 showed macrocytosis, with only 3 with MCV $\geq 110 \mathrm{fL}$; of the $66 / 253$ patients $(26.1 \%)$ with folate deficiency, only 10 showed macrocytosis, with only 1 with $\mathrm{MCV} \geq 110 \mathrm{fL}$.

\section{Glomerular filtration rate}

Only 45 patients $(17.2 \%)$ had severe CKD, while $68(26.0 \%)$ had stage $3 \mathrm{~b}$ and 75 (28.6\%) stage $3 \mathrm{a}$ CKD.

\section{Serum erythropoietin}

There was no statistically significant difference in EPO levels among different stages of CKD: $25.3 \pm 30.8$ $\mathrm{mUI} / \mathrm{mL}$ in stage $4-5,33.3 \pm 34.9$ in stage $3 \mathrm{~b}$, and $30.2 \pm 35.9$ in stage $3 \mathrm{a}$, with a median of $14.1,19.1$ and $18.1 \mathrm{mUI} / \mathrm{mL}$ respectively. There was no correlation

Table 4. Distribution of anemia types according to mean corpuscular volume (on 262 patients). Final column on the entire population of 277 patients.

\begin{tabular}{|c|c|c|c|c|}
\hline & $\begin{array}{c}\text { Microcytic } \\
15(5.7 \%)\end{array}$ & $\begin{array}{l}\text { Normocytic } \\
217(82.8 \%)\end{array}$ & $\begin{array}{l}\text { Macrocytic } \\
30(11.5 \%)\end{array}$ & $\begin{array}{c}\text { Total } \\
277(\%)\end{array}$ \\
\hline IDA only & 3 & 16 & - & $19(6.9)$ \\
\hline ACD only & 2 & 68 & 9 & $79(28.5)$ \\
\hline Vitamin B12 deficiency only & - & - & 1 & $1(0.3)$ \\
\hline Folate deficiency only & - & 1 & - & $1(0.3)$ \\
\hline CKD only* & - & 5 & 2 & $7(2.5)$ \\
\hline Clonal hemopathy only $^{\circ}$ & - & 7 & 2 & $9(3.2 \%)$ \\
\hline Overt bleeding anemia & NI & NI & NI & $13(4.7 \%)$ \\
\hline Thalassemic trait & NI & NI & NI & $2(0.7 \%)$ \\
\hline MFA & & & & $132(47.7)$ \\
\hline $\mathrm{IDA}+\mathrm{CKD} \pm \mathrm{B} 12 \pm \mathrm{Fo} \pm$ Hypot. & 1 & 8 & & $9(3.2)$ \\
\hline $\mathrm{IDA} \pm \mathrm{B} 12 \pm \mathrm{Fo} \pm$ Hypot. & 1 & 4 & 2 & $7(2.5)$ \\
\hline $\mathrm{ACD}+\mathrm{CKD} \pm \mathrm{B} 12 \pm \mathrm{Fo} \pm \mathrm{IDA} \pm$ Hypot. & 1 & 26 & 3 & $30(10.8)$ \\
\hline $\mathrm{ACD} \pm \mathrm{B} 12 \pm \mathrm{Fo} \pm \mathrm{IDA} \pm$ Hytpot. & 7 & 63 & 8 & $78(28.2)$ \\
\hline Other MFA $^{\#}$ & - & 5 & 3 & $8(2.9)$ \\
\hline Unclassificable anemia & - & 14 & - & $14(5.1)$ \\
\hline
\end{tabular}

IDA, iron deficiency anemia; $\mathrm{ACD}$, anemia of chronic disease; CKD, chronic kidney disease; NI, not included; MFA, multifactorial anemia; B12, vitamin B12 deficiency; Fo, folate deficiency; Hypot, hypothyroidism. *Including 3 cases with GFR 31-34 mL/min and no other cause of anemia; ${ }^{\circ}$ counted as clonal hemopathies even though only 1 was isolated; 6 plus ACD (3 of which + Fo); $1+$ Vit B12; 1 plus IDA; \#Hypot.(3) \pm B12 (2) \pm Fo (1) \pm CKD(2) \pm ACD (1) \pm Autoimmune hemolytic anemia (2) Tot ACD: 194 (70.0\%). 
between EPO and GFR ( $\mathrm{r}=0.018 ; \mathrm{P}=0.89)$; that between $\mathrm{EPO}$ and $\mathrm{Hb}$ was very poor $(\mathrm{r}=-0.344, \mathrm{P}<0.001)$.

\section{Thyroid function}

Twenty-eight patients had thyroid laboratory tests consistent with impaired thyroid function.

\section{Hemolysis}

Of the 35 patients with $\mathrm{LDH}>450 \mathrm{U} / \mathrm{L}$ and the 26 with reticulocytosis, only 2 showed a DAT positive and haptoglobin below $25 \mathrm{mg} / \mathrm{dL}$ and were classified as AIHA. Another 29 cases of positive DAT did not have any laboratory evidence of hemolysis.

\section{Types of anemia}

In the last column of Table 4 the diagnosis of all 277 patients is shown.

Of the 63 subjects qualifying for a diagnosis of IDA, only $19(6.9 \%)$ fulfilled all the following criteria: CRP $<10 \mathrm{mg} / \mathrm{L}$, GFR $>30 \mathrm{~mL} / \mathrm{min}$, normal Vit B12, folate and TSH levels, and had a final diagnosis of IDA only.

Of the 194 subjects qualifying for a diagnosis of ACD, 79 (28.5\%) were finally diagnosed as ACD only.

Of the 19 subjects qualifying for a diagnosis of vitamin B12 deficiency, only 1 had a final diagnosis of vitamin deficiency only, and only 1 out of 66 subjects with folate deficiency had a final diagnosis of folate deficiency only.

Of the 45 subjects qualifying for a diagnosis of CKD-related anemia, only 4 fulfilled required criteria, but 3 patients (with a GFR between 31 and $34 \mathrm{~mL} / \mathrm{min}$ and no other causes of anemia) were added, making the total diagnosis of CKD anemia only to $7(2.5 \%)$. Nine (3.2\%) clonal hemopathies were identified; nevertheless, in 8 out of 9 cases, additional possible causes of anemia were identified.

Of the 28 subjects qualifying for a diagnosis of hypothyroidism, none had a diagnosis of hypothyroidism only, since in all cases, other causes of anemia were present. UA was diagnosed only in 14 cases $(5.1 \%)$.

As a consequence of this all, most of the anemias were included in the category of MFA $(132,47.7 \%)$, with ACD (115), IDA (44) and CKD (41) as the most frequent subtypes combined in various associations with other possible etiologies; ACD was the most frequent subtype either as a single diagnosis (79, $28.5 \%)$ or overall $(194,70.0 \%)$.

\section{Discussion}

Iron restriction is a common mechanism of anemia pathogenesis in several clinical settings. Conditions that can be associated with iron-restricted erythropoiesis are represented by absolute iron deficiency, defined as the depletion of storage iron, ${ }^{7}$ and by functional iron deficiency, defined as the occurrence of iron-restricted erythropoiesis in the presence of normal or even increased amounts of iron stores. ${ }^{8}$ The first condition is considered synonymous of IDA, the most frequent single cause of anemia worldwide ${ }^{3}$ and the most frequent nutritional deficiency among elderly, ${ }^{9-17}$ where it is caused by chronic upper and lower gastrointestinal blood loss [benign and malignant lesions, angiodysplasias, drugs as salicylates, corticosteroids, non-steroidal antiinflammatory drugs (NSAID) and anticoagulants], reduced iron absorption (gastrectomy, celiac disease, Helicobacter pylori infection, autoimmune atrophic gastritis, proton pump inhibitors, and $\mathrm{H} 2$ blockers), and malnutrition. ${ }^{7,18,19}$ Functional ID, apart from patients on erythropoiesis-stimulating agents therapy, is caused by inflammation-related hepcidin increase with sequestration of iron in macrophages and hepatocytes and can be identified as the ACD..$^{20,21}$

The diagnosis and the differential diagnosis are challenging ${ }^{7,8,22,23}$ since true ID is often associated with inflammation, and this further complicates the interpretation of commonly used laboratory tests considered diagnostic among youngers (i.e., $\mathrm{MCV}$ and serum ferritin) but unreliable among elderly. In fact, microcytosis is present only in a minority of IDA patients ${ }^{15,18,19}$ (only $5.7 \%$ in the present study), and ferritin is an acute phase reactant plus tends to increase with age because of inflammaging, ${ }^{24}$ even in the absence of an evident inflammation/infection. On the other hand, the gold standard test to identify ID, namely the absence of stainable iron on a bone marrow (BM) biopsy, is not feasible in many elderly due to frailty and relevant comorbidities. ${ }^{18}$

Based on studies where SF levels were compared with BM stainable iron ${ }^{18}$ and expert opinions, ${ }^{7,8,19,22}$ and lacking more specific and sensitive tests (i.e. serum hepcidin, soluble $\mathrm{Tf}$ receptor and percent of hypochromic reticulocytes), we decided to select a level of SF of $100 \mu \mathrm{g} / \mathrm{L}$ (with a TSat $<20 \%$ ) as the threshold value below which diagnosis of ID could be made. Nonetheless, these cut-offs are largely used for therapeutic decisions, as underlined by a recent International expert opinion where i.v. iron treatment in patients with $\mathrm{SF}<100 \mu \mathrm{g} / \mathrm{L}$ (or TSat $<20 \%$ ) and heart failure, active intestinal bowel disease and dialysisCKD is suggested. ${ }^{23}$

This arbitrary threshold will likely overestimate the diagnosis of ID, since SF values of 30-50 to 100 $\mu \mathrm{g} / \mathrm{L}$ are consistent with either IDA and ACD. ${ }^{8,19}$

That said, our data are in agreement with the results of previous studies on elderly hospitalized patients ${ }^{13,14}$ and show a high prevalence of anemia $(54.5 \%)$ and in particular of mild anemia (188 
patients, $71.8 \%$ ), with almost half of these patients $(91 / 188,34.7 \%$ of the total) having very mild anemia (Table 2). These data raise the question as to whether this group of elderly with only very mild anemia should be considered anemic. In fact, almost always, they are admitted to hospital for any kind of infection $(33 / 91,36.2 \%)$ or an acute or subacute clinical deterioration of a preexisting condition (54/91, $59.3 \%$ ). In our opinion, they should be tested after a reasonable period of time from discharge to be definitively classified as anemics, and no intervention should be taken in the meanwhile.

As far as etiology is concerned, literature based on data collected among community-dwellers divides anemia etiology into 3 broad balanced categories: nutritional deficiency anemias, ACD, and UA., ${ }^{9,10,15-17}$

In the last decade, owing to new knowledge on the pathophysiology of $\mathrm{ACD},{ }^{8,20,21}$ studies on elderly hospitalized patients demonstrated that the frequency of the diagnosis of UA is consistently declining to less than $10 \%$. In contrast, the diagnosis of ACD (including CKD) raised to over $75 \% \cdot{ }^{12,13}$ We herein confirm these data, with ACD representing $70.0 \%$ of diagnoses.

However, most of these cases $(115,41.5 \%)$ were included among MFA. In Table 5 the main comorbidities as reported on discharge summaries are shown: 203 patients $(73.3 \%)$ were affected by at least one among chronic inflammatory conditions (heart failure, malignancy, diabetes, chronic obstructive pulmonary disease, CKD and connective tissue diseases) \pm acute infection and another 31 by acute infection only, making the total at $234,84.5 \%$.

Table 5. The most frequent diagnoses reported on discharge summaries (all patients, No. 277).

\begin{tabular}{lcc}
\hline Diagnoses & No. & $\mathbf{\%}$ \\
\hline Heart failure and other cardiopathies* & 125 & 45.1 \\
\hline Infections & 108 & 39.0 \\
Pneumonia & 51 & 18.4 \\
UTI & 37 & 13.4 \\
STI & 9 & 3.2 \\
Other & 10 & 3.6 \\
\hline Anemia & 59 & 21.3 \\
\hline Malignancy & 49 & 17.7 \\
Solid & 40 & 14.4 \\
Hematologic & 9 & 3.2 \\
\hline Diabetes & 45 & 16.2 \\
\hline Stroke & 35 & 12.6 \\
\hline COPD & 32 & 11.6 \\
\hline Hypertension & 32 & 11.6 \\
\hline
\end{tabular}

*Hypertensive, ischemic, valvular, dilatative. UTI, urinary tract infection; STI, soft tissue infection; $\mathrm{COPD}$, chronic obstructive pulmonary disease.
A high incidence of MFA was already reported by others $^{12,13}$, and these data are also confirmed in our study, where the diagnosis of MFA, with many possible etiologic combinations, resulted to be the most frequent (47.7\%) (Table 4).

As far as nutritional anemias, IDA was the most frequent (No. 63, 22.7\% of all patients and $42.6 \%$ of nutritional deficiencies), but only 19 patients $(6.9 \%$ of all and $30.2 \%$ of those with ID) fulfilled the characteristics for being classified as IDA only.

Vitamin B12 deficiency was observed in 19 cases $(7.5 \%)$ and folate deficiency in 66 cases $(26.1 \%)$.

This high prevalence of folate deficiency was in line with some data reported elsewhere ${ }^{12,14}$ and can be explained with the very old age of the population analyzed in this study, when malnutrition for fresh vegetables is widespread, in countries where fortified foods are uncommon as opposed to the U.S., where folate deficiency has disappeared as a result of fortification of flour. ${ }^{16,17}$

Since in these cases macrocytosis is expected, we analyzed MCV and found that among the 30 macrocytic anemias, only 6 cases (1 isolated) were deficient in vitamin B12, while 11 (all in the context of MFA) were folate deficient. Moreover, only 3 and 1 patients respectively showed an $\mathrm{MCV} \geq 110 \mathrm{fL}$, commonly considered diagnostic for these conditions.

This is in accordance with the findings of Savage, ${ }^{25}$ who demonstrated that in hospitalized patients the most common cause of macrocytosis was medication (37\%) (among elderly, most commonly metformin, proton pump inhibitors, and H2-receptor blockers), followed by alcoholism (26\%), with vitamin B12 and/or folate deficiency, MDS and liver disease accounting each for only $6 \%$ of cases. High MCV is also a possible marker of MDS, but none of our patients fulfilled the proposed minimal diagnostic criteria of $M D S,{ }^{26}$ since invasive testing was not performed concerning old age and clinical conditions. Among the 22 patients with monocytosis though, 2 showed peripheral blood features compatible with chronic myelomonocytic leukemia, which together with 2 cases of MDS previously known, makes the potential prevalence of this disease among our patients at $1.52 \%$, lower than the expected prevalence of around $5-15 \%$ reported in studies where patients were properly investigated. ${ }^{16,27}$

Another possible cause of macrocytosis is hypothyroidism, but no patient was found to be anemic based on thyroid dysfunction only.

The diagnosis of anemia secondary to CKD was less frequent $(2.5 \%)$ than expected, in part due to the high prevalence of MFA which masked the actual prevalence of CKD, in part because the GFR threshold below which the diagnosis of anemia of CKD is made $(30 \mathrm{~mL} / \mathrm{min}$ ) appears too restrictive, considering that 
the U.S. guidelines for EPO therapy indicate a GFR cut-off of $<60 \mathrm{~mL} / \mathrm{min}$ to be considered for reimbursement ${ }^{22}$ and the fact that is very likely that even GFRs compatible with stage 3 CKD have an impact on the co-pathogenesis of anemia; and, in our cohort, 68 patients (49 of which in association with ACD) had a stage $3 \mathrm{~b}$ CKD.

Dosing serum EPO was no helpful in making the diagnosis since, accordingly with data showing inappropriately low levels of EPO in elderly subjects with $\mathrm{CKD}, \mathrm{ACD}$, and $\mathrm{UA},{ }^{28}$ we found low levels of EPO with no significant difference among CKD stages, no correlation with GFR and very poor correlation with $\mathrm{Hb}$.

Not even reticulocyte count/RI was helpful, since the majority of our patients was affected by hypoproliferative anemia, not to mention that underlying $\mathrm{CKD}$, MDS, or nutritional deficiencies may blunt the ability of the patient's BM to respond properly.

In only 2 patients, an AIHA was diagnosed, compared with a positive DAT found in 31 cases. But a positive DAT without hemolysis can be found in the $0.1 \%$ of healthy people and up to $15 \%$ of hospitalized patients, resulting from spontaneous red blood cell agglutination, elevated serum immunoglobulins, cardiolipin antibodies, infection, reticulocytosis, drugs (mainly $\beta$-lactam antimicrobials and NSAID) and technical problems related to sample processing. ${ }^{29,30}$

A precise etiology of anemia (i.e. UA) was not found in only 14 patients (5.1\%), confirming that extensive evaluation narrows the possibility of missing the diagnosis. This small group of 7 males and 7 females had a mean age of 81.7 years (75-95), a mean $\mathrm{Hb}$ of $117 \mathrm{gr} / \mathrm{L}$ (96-128), all were normocytic, $11 / 14$ patients showed only very mild anemia and $11 / 14$ had a stage $3 \mathrm{CKD}$.

\section{Conclusions}

The main finding of the present study was the very high rate of ACD and MFA among the old and oldestold patients hospitalized in an internal medicine ward. This is due to the addition, with the progression of age, of many comorbidities, each one possible cause of anemia itself.

These data have important clinical implications. From the diagnostic point of view, a full evaluation of the anemic patient may take several steps to complete an extensive workup considering that even when suspecting the presence of ID or ACD, other clinically essential diagnoses are likely to be present in the vast majority of these patients. Moreover, classic diagnostic algorithms for anemia, such as those based on MCV or reticulocytes, are designed to identify single etiologies but have limited value among the elderly. So that, in the work-up of an elderly patient with anemia a comprehensive hematologic evaluation in search for the five most frequent causes of anemia (iron, vitamin B12, and folate deficiencies, inflammation and CKD) should be systematically undertaken: complete iron studies (serum iron, Tf, TSat, and SF), Vit B12 and folate levels, GFR and CRP. Thyrotropin stimulating hormone, FT4, EPO, reticulocytes, DAT, and haptoglobin should be requested upon indication as a second step, while BM examination is indicated only if blood studies are unrewarding. Nonetheless, the widespread use of tests such as serum hepcidin, serum Tf receptor and/or sTfR-ferritin index and percent hypochromic reticulocytes is warranted, in particular to better identify patients with inflammation and iron deficiency.

From the therapeutic point of view, nutritional deficiencies should be corrected at first, with a particular indication to i.v. iron in the setting of inflammation. EPO therapy may also be indicated in patients with concomitant CKD and/or inflammation and/or MDS.

A final consideration: anemia, although associated with several adverse outcomes including more extended hospitalization and increased morbidity and mortality, ${ }^{18,19}$ is not taken into deserved consideration by physicians if, even in a prospective study where doctors are aware that they are collecting data on this disease, the diagnosis of anemia is reported on discharge summaries only in $21.3 \%$ of cases (Table 5).

\section{References}

1. Ouchi Y, Rakugi H, Arai H, et al. Redefining the elderly as aged 75 years and older: proposal from the Joint Commettee of Japan Gerontological Society and the Japan Geriatrics Society. Geriatr Gerontol Int 2017;17: 1045-7.

2. Transgenerational.org. Demographics of Aging... Avalable from: http://transgenerational.org/aging/ demographics.htm. Accessed: April 2016.

3. Kassebaum NJ; on behalf of GBD 2013 Anemia Collaborators. The global burden of Anemia. Hematol Oncol Clin N Am 2016;30:247-308.

4 . Gaskell H, Derry S, Moore RA, McQuay HJ. Prevalence of anaemia in older persons: systematic review. BMC Geriatrics 2008;8:1-8.

5. Levey AS, Stevens LA, Schmid CH, et al. A new equation to estimate glomerular fintration rate. Ann Intern Med 2009;150:604-12.

6. Blanc B, Finch CA, Hallberg L, et al. Nutritional anemias. Report of a WHO scientific group. World Health Organ Tech Rep Ser 1968;405:5-37.

7. Camaschella C. Iron deficiency. Blood 2019;133:30-9.

8. Goodnough LT, Nemeth E, Ganz T. Detection, evaluation, and management of iron-restricted erythropoiesis. Blood 2010;116:4754-61.

9. Stauder R, Valent P, Theurl I. Anemia at older age: 
etiologies, clinical implications, and management. Blood 2018;131:505-14.

10. Guralnik JM, Eisenstaedt RS, Ferrucci L, et al. Prevalence of anemia in persons 65 years and older in the United States: evidence of a high rate of unexplained anemia. Blood 2004;104:2263-8.

11. Tettamanti M, Lucca U, Gandini F, et al. Prevalence, incidence and types of mild anemia in elderly: the "Health and Anemia" population-based study. Haematologica 2010;95:1849-56.

12. Petrosyan DI, Blaison G, Andrès E, Federici L. Anaemia in the elderly: an aetiologic profile of a prospective cohort of 95 hospitalised patients. Eur J Intern Med 2012;23:534-8.

13. Zaninetti C, Klersy C, Scavariello C, et al. Prevalence of anemia in hospitalized internal medicine patients: correlations with comorbidities and length of hospital stay. Eur J Intern Med 2018;51:11-7.

14. Migone De Amicis M, Poggiali E, Motta I, et al. Anemia in elderly hospitalized patients: prevalence and clinical impact. Intern Emerg Med 2015;10:581-6.

15. Bach V, Schruckmayer G, Sam I, et al. Prevalence and possible causes of anemia in the elderly: a crosssectional analysis of a large European university hospital cohort. Clin Interv Aging 2014;9:1187-96.

16. Price EA, Mehra R, Holmes TH, Schrier SL. Anemia in older persons: etiology and evaluation. Blood Cells Mol Dis 2011;46:159-65.

17. Artz AS, Thirman MJ. Unexplained anemia predominates despite an intensive evaluation in a racially diverse cohort of older adults from a referral anemia clinic. J Gerontol 2011;66:925-32.

18. Girelli D, Marchi G, Camaschella C. Anemia in the Elderly. HemaSphere 2018;2:e40.

19. Busti F, Campostrini N, Martinelli N, Girelli D. Iron deficiency in the elderly population, revisited in the hepcidin era. Front pharmacol 2014;5:83.

20. Weiss G, Goodnough LT. Anemia of chronic disease. N Engl J Med 2005;352:1011-23.

21. Weiss G, Ganz T, Goodnough LT. Anemia of inflammation. Blood 2019;133:40-50.

22. Goodnough LT, Schrier SL. Evaluation and management of anemia in the elderly. Am J Hematol 2014;89:88-96.

23. Cappellini MD, Comin-Colet J, de Francisco A, et al. Iron deficiency across chronic inflammatory conditions: International expert opinion on definition, diagnosis and management. Am J Hematol 2019;92:1068-78.

24. Franceschi C, Bonafè M, Valensin S, et al. Inflammaging. An evolutionary perspective on immunosenescence. Ann N Y Acad Sci 2000;908:244-54.

25. Savage DG, Ogundipe A, Allen RH, et al. Etiology and diagnostic evaluation of macrocyrosis.Am J Med Sci 2000;6:343-52.

26. Valent P, Orazi A, Steensma DP, et al. Proposed minimal diagnostic criteria for myelodysplastic syndromes (MDS) and potential pre-MDS conditions. Oncotarget 2017;8:73483-500.

27. Buckestein R, Jang K, Friedlich J, et al. Estimating the prevalence of myelodysplastic syndromes in patients with unexplained cytopenias: a retrospective study of 322 bone marrows. Leuk Res 2009;33:1313-8.

28. Gowanlock Z, Stiram S, Martin A, et al. Erythropoietin levels in elderly patients with anemia of unknown etiology. PLos One 2016;11:e0157279.

29. Zantek ND, Koepsell SA, Tharp DR, Cohn CS. The direct antiglobulin test: a critical step in the evaluation of hemolysis. Am J Hematol 2012;87:707-9.

30. Parker V, Tormey CA. The direct antiglobulin test. Arch Pathol Lab Med 2017;141:305-10. 